\title{
Expert's comment concerning Grand Rounds case entitled "Late collapse osteoporotic vertebral fracture in an elderly patient with neurological compromise" (D. Ruiz Picazo, J. Ramírez Villaescusa, E. Portero Martínez, F. Doñate Pérez)
}

\author{
Ulrich Seidel
}

Received: 1 September 2014/Revised: 9 September 2014/ Accepted: 9 September 2014/Published online: 26 September 2014 (C) Springer-Verlag Berlin Heidelberg 2014

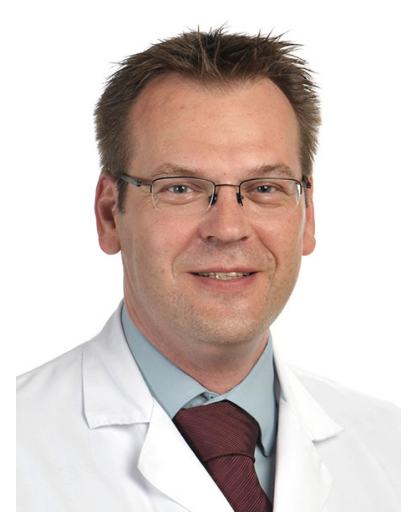

This article describes very well a common and increasing problem in the daily routine of the spine surgeon [1]. The mentioned problem is more frequent than literature would suppose.

The combination of factors that may lead to severe complications in the natural history of osteoporotic fractures is worked out very well. The relevant factors to identify patients at risk are described in a very complete way, as well as the diagnostic evaluation.

The chosen treatment is adequate. It has been a good choice to decompress the spinal canal including resection of the posterior wall fragments, because after 3 months period, since the fracture occurred an indirect clearance of the canal by reduction only is mostly not possible even in osteoporotic fractures with pseudarthrosis. The extension of the stabilization two levels above and below is

U. Seidel $(\bowtie)$

Department of Orthopaedic Surgery and Traumatology,

Inselspital, University Hospital Bern, Freiburgstrasse,

3010 Bern, Switzerland

e-mail: ulrich.seidel@insel.ch appropriate because more anchor points are needed with poor bone quality.

Just the amount of cement applied for screw augmentation could be criticized. The X-rays show only little cement around the screws of the adjacent vertebrae. This amount of cement is not able to significantly increase the stability of the screws in true osteoporotic bone.

The stabilization in this case probably worked because of the longer construct and because there was no need for reduction and therefore only little tension forces on the implants. One could argue also, that in the present case the osteoporosis might have been not too severe, even more, as no quantification of the bone quality (DEXA) is mentioned in the article.

Beside neurological complications, the even more frequent indication for stabilization of the osteoporotic spine is severe post-fractural deformity, which can be immobilizing.

In this comment, I would therefore like to focus on the difficulties of fixation techniques in the osteoporotic spine, because this is still a controversial issue.

The technique used by the article authors is adequate in this case, because there is no severe deformity. If more correction is needed, anterior column reconstruction is mandatory.

In the old patient, surgical trauma and time of procedure should be reduced to a minimum. Our own practice is to perform an open approach for the necessary decompression and perform the further instrumentation percutaneously. Several percutaneous implants offer all necessary tools for reduction as special reduction tools, long screw extension threads, combination of mono- and polyaxial screws and the possibility for cement augmentation.

Screw augmentation is the key for stable fixation in the osteoporotic spine [2-4]. Other techniques as varying 
screw angulation, thread design, laminar bands, hooks, etc. might have advantages in normal bone but have not proven superior performance in the osteoporotic spine $[5,6]$.

Longer constructs are necessary compared to normal bone to achieve sufficient stability [7]. This can, due to the lever arm created by the longer fixation, lead to additional problems at the adjacent levels as cut-out of the screws at the end level or fracture of the adjacent vertebral body. Our practice is therefore to augment also the screws at the end level as well as the first uninstrumented vertebral body.

With a bad lever arm and a strong fixation, you might create instability up to subluxation with neurological deficits at the adjacent disc level. To prevent this, stabilization in an acceptable balance is the most helpful instrument.

This means that often additional support of the anterior column or shortening of the posterior column might be necessary [8-10]. Expandable cages offer the advantage that they can be introduced by a dorsolateral approach during the posterior surgery or by a minimal-invasive lateral or thoracoscopical approach. With the most implants an additional reduction can be achieved. Subsidence of the cage into the adjacent endplates is a common problem, so our practice is to aggressively augment the adjacent vertebral bodies during posterior instrumentation.

Shortening of the posterior column is a challenging procedure, might have a longer operation time and blood loss and the risk of deterioration especially of pre-existing neurological symptoms. In experienced hands it is nevertheless a helpful instrument for balancing also the osteoporotic spine.

In summary, surgical treatment of the osteoporotic spine is challenging. In my opinion the best way to avoid complications of osteoporotic spine fractures is to perform percutaneous augmentation in an early stage. The bad bone quality and the often bad general condition of the patients need special considerations. Blood loss and time of surgery can be reduced by using minimal-invasive techniques. Longer constructs, cement augmentation of the screws and adequate balancing of the spine are keys for success but many problems continue to be unsolved. Even after extensive procedures the profit for severely compromised patients is quite obvious.
Conflict of interest None.

\section{References}

1. Ruiz Picazo D, Ramírez Villaescusa J, Portero Martínez E, Doñate Pérez F (2014) Late collapse osteoporotic vertebral fracture in an elderly patient with neurological compromise. Eur Spine J. doi:10.1007/s00586-013-2751-3

2. Burval DJ, McLain RF, Milks R, Inceoglu S (2007) Primary pedicle screw augmentation in osteoporotic lumbar vertebrae: biomechanical analysis of pedicle fixation strength. Spine (Phila Pa 1976) 32(10):1077-1083

3. Cho W, Cho SK, Wu C (2010) The biomechanics of pedicle screw-based instrumentation. J Bone Joint Surg $\mathrm{Br}$ 92(8):1061-1065. doi:10.1302/0301-620X.92B8.24237

4. Sawakami K, Yamazaki A, Ishikawa S, Ito T, Watanabe K, Endo N (2012) Polymethylmethacrylate augmentation of pedicle screws increases the initial fixation in osteoporotic spine patients. J Spinal Disord Tech 25(2):E28-E35. doi:10.1097/BSD. Ob013e318228bbed

5. Santoni BG, Hynes RA, McGilvray KC, Rodriguez-Canessa G, Lyons AS, Henson MA, Womack WJ, Puttlitz CM (2009) Cortical bone trajectory for lumbar pedicle screws. Spine J 9(5):366-373. doi:10.1016/j.spinee.2008.07.008

6. Mac-Thiong JM, Levasseur A, Parent S, Petit Y (2014) The influence of proximal anchors on the risk of proximal junctional fracture in the osteoporotic spine: biomechanical comparison between pedicle screws and transverse process hooks. J Spinal Disord Tech 27(2):E49-E54. doi:10.1097/BSD. Ob013e318292b914

7. Patil S, Rawall S, Singh D, Mohan K, Nagad P, Shial B, Pawar U, Nene A (2013) Surgical patterns in osteoporotic vertebral compression fractures. Eur Spine J 22(4):883-891. doi:10.1007/ s00586-012-2508-4

8. Uchida K, Kobayashi S, Matsuzaki M, Nakajima H, Shimada S, Yayama T, Sato R, Baba H (2006) Anterior versus posterior surgery for osteoporotic vertebral collapse with neurological deficit in the thoracolumbar spine. Eur Spine J 15(12):1759-1767

9. Okuda S, Oda T, Yamasaki R, Haku T, Maeno T, Iwasaki M (2012) Surgical outcomes of osteoporotic vertebral collapse: a retrospective study of anterior spinal fusion and pedicle substraction osteotomy. Global Spine J 2(4):221-226. doi:10.1055/s0032-1331461

10. Suk SI, Kim JH, Lee SM, Chung ER, Lee JH (2003) Anteriorposterior surgery versus posterior closing wedge osteotomy in posttraumatic kyphosis with neurologic compromised osteoporotic fracture. Spine (Phila Pa 1976) 28(18):2170-2175 